\title{
Racial disparities in the diagnosis and management of trigeminal neuralgia
}

\author{
Kevin Reinard, MD, ${ }^{1}$ David R. Nerenz, PhD, ${ }^{1}$ Azam Basheer, MD,, Rizwan Tahir, MD, ${ }^{1}$ \\ Timothy Jelsema, BS, MS, ${ }^{2}$ Lonni Schultz, PhD, ${ }^{1}$ Ghaus Malik, MD, ${ }^{1}$ Ellen L. Air, MD, PhD, ${ }^{1}$ and \\ Jason M. Schwalb, MD ${ }^{1,2}$
}

1Department of Neurosurgery, Henry Ford Medical Group, and 'Wayne State University School of Medicine, Detroit, Michigan

OBJECTIVE A number of studies have documented inequalities in care and outcomes for a variety of clinical conditions. The authors sought to identify racial and socioeconomic disparities in the diagnosis and treatment of trigeminal neuralgia (TN), as well as the potential underlying reasons for those disparities, which could serve as areas of focus for future quality improvement initiatives.

METHODS The medical records of patients with an ICD-9 code of 350.1, signifying a diagnosis of TN, at the Henry Ford Medical Group (HFMG) in the period from 2006 to 2012 were searched, and clinical and socioeconomic data were retrospectively reviewed. Analyses were conducted to assess potential racial differences in subspecialty referral patterns and the specific type of treatment modality undertaken for patients with TN.

RESULTS The authors identified 652 patients eligible for analysis. Compared with white patients, black patients were less likely to undergo percutaneous ablative procedures, stereotactic radiosurgery, or microvascular decompression $(p<0.001)$. However, there was no difference in the likelihood of blacks and whites undergoing a procedure once they had seen a neurosurgeon ( $67 \%$ vs $70 \%$, respectively; $p=0.712$ ). Blacks and whites were equally likely to be seen by a neurologist or neurosurgeon if they were initially seen in either the emergency room (38\% vs $37 \%, p=0.879$ ) or internal medicine ( $48 \%$ vs 50\%, $p=0.806$ ). Among patients diagnosed (268 patients) after the 2008 publication of the European Federation of Neurological Societies and the American Academy of Neurology guidelines for medical therapy for TN, fewer than $50 \%$ were on medications sanctioned by the guidelines, and there were no statistically significant racial disparities between white and black patients $(p=0.060)$.

CONCLUSIONS According to data from a large database from one of the nation's largest comprehensive health care systems, there were significant racial disparities in the likelihood of a patient undergoing a procedure for TN. This appeared to stem from outside HFMG from a difference in referral patterns to the neurologists and neurosurgeons.

http://thejns.org/doi/abs/10.3171/2015.11.JNS151177

KEY WORDS trigeminal neuralgia; racial disparity; socioeconomic status; chronic pain management; functional neurosurgery; pain

$\mathrm{E}$ PIDEMIOLOGICAL studies have estimated the incidence rate of trigeminal neuralgia $(\mathrm{TN})$ in a range from 11.0 to 42.0 cases per 100,000 people per year with a female preponderance. ${ }^{17}$ While TN can afflict people of any age, the majority of patients are between the ages of 50 and 60 years. ${ }^{10}$ A paucity of literature is dedicated to the racial epidemiology of TN, although some epidemiological studies have been performed at the Mayo Clinic in
Rochester, Minnesota, ${ }^{13,14}$ and the University of São Paulo in Brazil..$^{15}$ While the Mayo study found no difference in the incidence of TN among different races, the Brazilian study revealed a higher incidence of TN in whites than in other races.

The European Federation of Neurological Societies (EFNS) and the American Academy of Neurology (AAN) have promulgated guidelines for the medical and surgi-

ABBREVIATIONS AAN = American Academy of Neurology; EFNS = European Federation of Neurological Societies; ER = emergency room; HFMG = Henry Ford Medical Group; $\mathrm{MS}$ = multiple sclerosis; MVD = microvascular decompression; PCTR = percutaneous rhizotomy; SRS = stereotactic radiosurgery; TN = trigeminal neuralgia. SUBMITTED May 21, 2015. ACCEPTED November 16, 2015.

INCLUDE WHEN CITING Published online March 11, 2016; DOI: 10.3171/2015.11.JNS151177. 
cal treatment of TN since 2008., ${ }^{1,2,4}$ Radiation therapy in the form of Gamma Knife surgery or other stereotactic radiosurgery (SRS); ablative procedures such as percutaneous rhizotomy (PCTR), balloon compression, glycerol rhizotomy, or radiofrequency ablation; and microvascular decompression (MVD) are accepted treatment options for patients with medically refractory $\mathrm{TN} .{ }^{9}$

The current study was launched after we noted that a seemingly smaller number of black patients compared with the number of white patients were being referred for the surgical management of TN despite a large black population in Southeast Michigan. According to the 2010 US Census, of the 4,704,743 citizens in Southeast Michigan, $68.5 \%$ were white, $21.6 \%$ black, $3.9 \%$ Hispanic, and $3.6 \%$ Asian (Census.gov). Although prior studies have noted racial disparities in the performance of inpatient $\mathrm{TN}$ procedures, ${ }^{12,18}$ we elected to examine racial disparities in the diagnosis, medical management, and both inpatient and outpatient procedures for the treatment of $\mathrm{TN}$ in a large, urban health system with a diverse patient population and large referral base. Our primary analytical goal was to examine steps in the diagnosis, referral, and treatment sequence to identify the points at which racial disparities appeared in that sequence. We hypothesized that black patients are more frequently diagnosed in the emergency room (ER) rather than in the outpatient clinic setting and, perhaps because of lower rates of health insurance coverage and reduced access to health care, would not get referrals to outpatient subspecialty clinics or would be lost to follow-up more often than their white counterparts.

\section{Methods}

After receiving approval from our institutional review board, we queried an administrative database to identify patients with a diagnostic code of 350.1 (TN) who had been evaluated and treated for facial pain at the Henry Ford Medical Group (HFMG) between 2006 and 2012. The database covered care provided by HFMG physicians in 2 inpatient facilities, approximately 36 outpatient facilities, and emergency departments located in both inpatient and 3 of the outpatient facilities. We performed a retrospective chart review and developed a database of the identified patients, abstracting information about patient age; sex; race (white, black, or other); imputed household income based on geocoded census tract (when available) or residential zip code (in US dollars); type of health care coverage at TN diagnosis (Medicare, Medicaid, private insurance, or self-pay [that is, uninsured]); laterality of symptoms; presence of atypical features such as constant, dull facial pain or numbness resulting from facial trauma or oral surgery; history of multiple sclerosis (MS); health care setting of initial diagnosis (ER, specific HFMG outpatient clinic, or sites other than HFMG); any referrals to subspecialty clinics; medications prescribed; and procedure performed (SRS, PCTR, or MVD); as well as the time between diagnosis and any procedure performed. Data on age at TN diagnosis; atypical features such as constant, dull facial pain, numbness resulting from facial trauma or oral surgery; and history of MS were obtained from notes made by neurologists or neurosurgeons. The site of TN diagnosis was abstracted from notes made by neurologists and neurosurgeons as well. If a neurologist or neurosurgeon did not see the patient, the records were still abstracted for the site of initial diagnosis. Data regarding TN medications were abstracted from listings of medications or from the sections labeled "history of present illness" in the clinical notes.

\section{Statistical Analysis}

Pairwise comparisons of the racial groups (white vs black, white vs other, and black vs other) were performed. Chi-square tests were used for categorical and binary characteristics, whereas 2-sample t-tests and Wilcoxon tests were used for age, number of medications, and median household income. Logistic regression methods were used to adjust for socio-demographic information when assessing racial differences. Significance was set at a $p$ value of 0.05 with no adjustments for multiple comparisons. Statistical analyses were performed using SAS version 9.2 (SAS Institute Inc.).

\section{Results}

Twenty-one of 673 patients were of unknown race; thus, 652 patients were included in our analyses. Missing data regarding year of and patient age at diagnosis (57 patients) and duration between diagnosis and treatment (28 patients) were coded as missing and thus not included in the final analysis. For patients in whom the place of diagnosis was not documented in our electronic medical records (120 patients), we assumed that the diagnosis had been rendered outside of our institution.

Six hundred fifty-two patients were included in the final analysis, 484 (74\%) of whom were female. Among the 652 patients, $409(63 \%)$ were white, $196(30 \%)$ were black, and 47 (7\%) were another race (Fig. 1). Mean age at the time of diagnosis was 60.3 years (SD \pm 15.2 ), with a range of 17 to 94 years. White patients were an average of 7 years older than black patients $(p<0.001)$ and 4 years older than other-race patients $(\mathrm{p}=0.107)$ at the time of diagnosis. The male/female ratio was similar across the 3 racial groups. White patients had a higher rate of MS than black patients $(6 \%$ vs $2 \%, p=0.028)$. The distribution of the type of insurance coverage differed between the white and black patients: white patients were more likely to have Medicare coverage $(\mathrm{p}=0.019)$, whereas black patients were more likely to have Medicaid coverage $(\mathrm{p}<0.001)$. The uninsured rate was not different among the 3 racial groups. Table 1 summarizes the key characteristics of patients included in the study.

The overall rate of undergoing at least 1 procedure was $29 \%$ of all patients (190 of 652), with $20 \%$ having at least $1 \mathrm{MVD}, 5 \%$ having at least $1 \mathrm{SRS}$, and $10 \%$ having at least 1 PCTR. As expected from our initial impression, black patients were less likely than white patients to undergo any procedures ( $21 \%$ vs $34 \%$, respectively, $\mathrm{p}<0.001)$. White patients were more likely than black patients to undergo one of the ablative procedures ( $12 \%$ vs $7 \%, \mathrm{p}=0.035)$, SRS (6\% vs $3 \%, \mathrm{p}=0.047)$, or MVD ( $24 \%$ vs $15 \%, \mathrm{p}=0.012)$. White patients were more likely than other-race patients to undergo any procedures ( $34 \%$ vs $17 \%, \mathrm{p}=0.016)$, including 


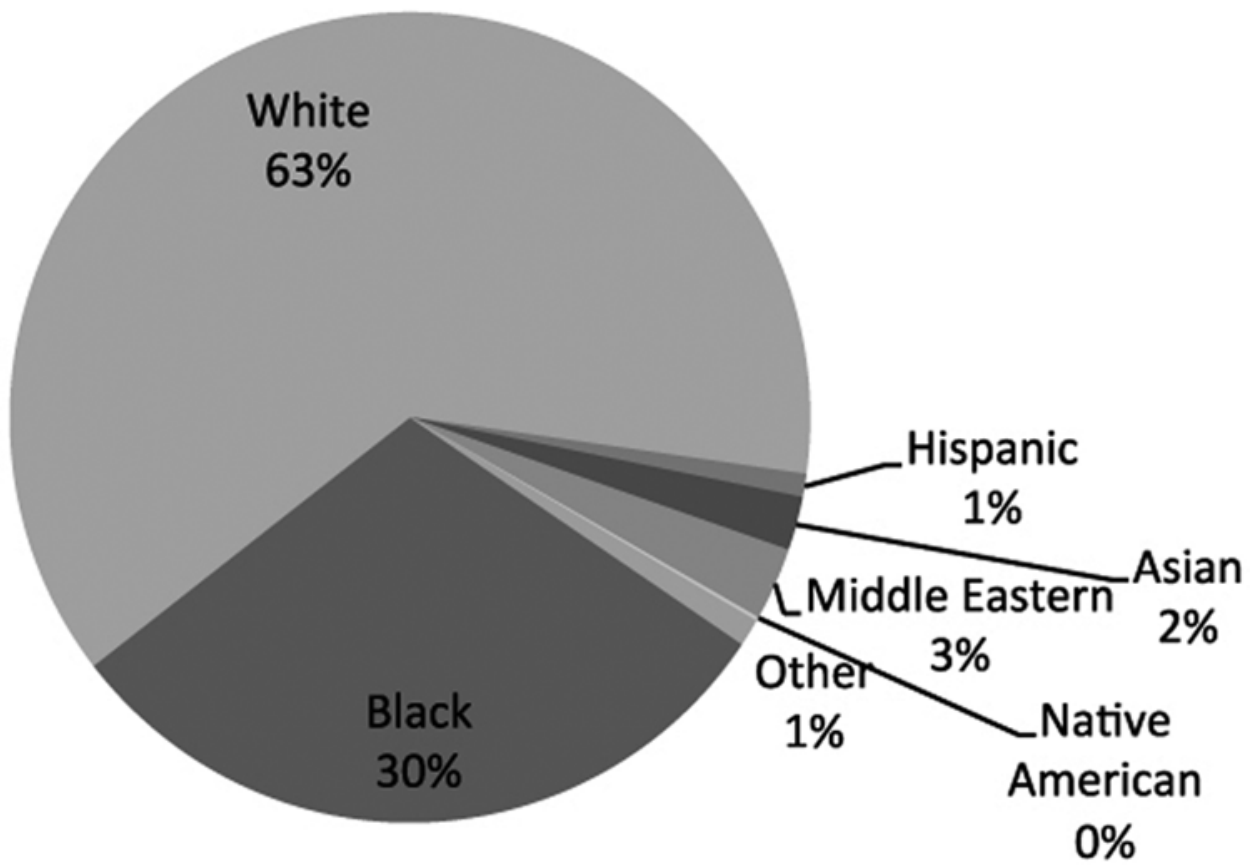

FIG. 1. Racial distribution of 652 patients with TN.

MVD (24\% vs 6\%, $\mathrm{p}=0.005)$. No statistically significant differences in undergoing any procedure were detected between the black and other-race patients. These differences in undergoing any procedure between whites and other racial groups remained after adjusting for age, type of insurance, and median household income (Table 2).

\section{Possible Mechanisms for Treatment Disparities \\ Time Since Initial Diagnosis}

Of those patients who underwent any procedure, no differences were detected among the racial groups for the time from initial TN diagnosis to the time of the procedure, with a median of 2 years for whites and blacks and 1.5 years for other races (Table 3 ).

\section{Choice of Treatment by Neurosurgeons}

Of the 190 patients undergoing at least 1 procedure, $180(95 \%)$ were seen by an HFMG neurosurgeon. Among the 266 TN patients seen by HFMG neurosurgeons, there was no difference between white (70\%) and black (67\%) patients $(p=0.712)$ in the rate of undergoing at least 1 procedure. Other-race patients had a significantly lower rate of undergoing a procedure (44\%) than white patients $(\mathrm{p}=$ 0.032 ) and showed a trend toward a lower rate of procedures than black patients $(p=0.086)$. These patterns by race were specifically observed for MVD; that is, there were no differences between white and black patients $(50 \%$ vs $48 \%, \mathrm{p}=0.81)$, and there were significant differences between other-race patients $(19 \%)$ and the 2 other racial groups $(\mathrm{p}=0.016$ for white and $\mathrm{p}=0.034$ for black). No racial differences were detected in the rates of PCTR (white $25 \%$, black $22 \%$, and other $13 \%$, overall $\mathrm{p}=0.51$ ) or SRS (white $12 \%$, black 9\%, and other $13 \%$, overall $\mathrm{p}=$ 0.768).

There were no statistical differences based on age and type or lack of insurance in the likelihood of a patient seen by a neurosurgeon to undergo a procedure (Table 2). For the subset of patients seen by HFMG neurosurgery, patients with higher incomes were slightly less likely to undergo a procedure (OR for every increase of $\$ 10,000$ was $0.89,95 \%$ CI $0.79-0.99, \mathrm{p}=0.028$ ).

\section{Patterns of Referral to Neurosurgery}

The HFMG comprises more than 1100 physicians and researchers from over 40 different specialties. With 2 main hospital branches and 26 medical centers, including 8 emergency medicine centers, the HFMG serves all of Southeastern Michigan. In 2009, a new 191-bed hospital was constructed in the northeastern suburbs of Detroit. These centers combined reported nearly 3.4 million outpatient visits and more than 73,000 surgical procedures in 2014.

A significant racial difference was detected in the initial setting of TN diagnosis in comparing white and black patients $(\mathrm{p}<0.001)$, as well as in comparing white patients to other-race patients $(p=0.008)$ : White patients had a higher rate of initial diagnosis outside of HFMG as compared with blacks (36\% vs $16 \%, \mathrm{p}<0.001)$ and corresponding lower rates of diagnosis in our institution's ER and internal medicine department $(8 \%$ vs $31 \%$, p < 0.001 ; $15 \%$ vs $23 \%, \mathrm{p}=0.015$, respectively). Compared with other-race patients, whites also had lower rates of diagnosis in our ER $(8 \%$ vs $26 \%, \mathrm{p}<0.001)$. Besides the departments of internal medicine, neurology, and neurosurgery, patients with TN can be seen within the HFMG at 1 of the 8 ERs. To our knowledge, no algorithm exists within the emergency department for the management and evaluation of patients with TN. No differences were seen between black and other-race patients for the initial setting of diagnosis (Table 1). 


\begin{tabular}{|c|c|c|c|c|c|c|c|}
\hline \multirow[b]{2}{*}{ Variable } & \multirow[b]{2}{*}{ All Patients } & \multirow[b]{2}{*}{ White } & \multirow[b]{2}{*}{ Black } & \multirow[b]{2}{*}{ Other } & \multicolumn{3}{|c|}{$p$ Value } \\
\hline & & & & & $\begin{array}{l}\text { White vs } \\
\text { Black }\end{array}$ & $\begin{array}{c}\text { White vs } \\
\text { Other }\end{array}$ & $\begin{array}{l}\text { Black vs } \\
\text { Other }\end{array}$ \\
\hline No. of patients & 652 & 409 & 196 & 47 & & & \\
\hline $\begin{array}{l}\text { Mean age }( \pm S D) \text { at diagnosis } \\
\text { in yrs } \dagger\end{array}$ & $60.3 \pm 15.2$ & $62.8 \pm 14.6$ & $55.7 \pm 15.4$ & $59.1 \pm 14.7$ & $<0.001$ & 0.107 & 0.172 \\
\hline Sex & & & & & 0.299 & 0.911 & 0.497 \\
\hline Male & $168(26)$ & $110(27)$ & $45(23)$ & $13(28)$ & & & \\
\hline Female & $484(74)$ & $299(73)$ & $151(77)$ & $34(72)$ & & & \\
\hline Median household income (IQR) & $\begin{array}{l}\$ 51,673(\$ 37,690- \\
\quad \$ 68,036)\end{array}$ & $\begin{array}{l}\$ 60,357(\$ 46,607- \\
\quad \$ 76,414)\end{array}$ & $\begin{array}{l}\$ 37,143(\$ 26,862- \\
\quad \$ 47,708)\end{array}$ & $\begin{array}{l}\$ 44,792(\$ 28,658- \\
\quad \$ 65,086)\end{array}$ & $<0.001$ & $<0.001$ & 0.027 \\
\hline Insurance & & & & & $<0.001$ & 0.232 & 0.227 \\
\hline None & $77(12)$ & $56(14)$ & $18(9)$ & $3(6)$ & & & \\
\hline Private/self pay & $391(60)$ & $232(57)$ & $125(64)$ & $34(72)$ & & & \\
\hline Medicare & $150(23)$ & $106(26)$ & $34(17)$ & $10(21)$ & & & \\
\hline Medicaid & $19(3)$ & $6(1)$ & $13(7)$ & $0(0)$ & & & \\
\hline Other & $15(2)$ & $9(2)$ & $6(3)$ & $0(0)$ & & & \\
\hline Symptom/side & & & & & 0.382 & 0.267 & 0.148 \\
\hline No side & $145(22)$ & $88(22)$ & $52(26)$ & $5(11)$ & & & \\
\hline Unilat & $472(72)$ & $299(73)$ & $134(68)$ & $39(83)$ & & & \\
\hline Atypical & $28(4)$ & $19(5)$ & $7(4)$ & $2(4)$ & & & \\
\hline Bilat & 7 (1) & $3(1)$ & $3(2)$ & $1(2)$ & & & \\
\hline Yr of diagnosis $†$ & & & & & 0.065 & 0.296 & 0.945 \\
\hline$<2000$ & $66(11)$ & $47(13)$ & $15(8)$ & $4(9)$ & & & \\
\hline $2000-2009$ & $363(61)$ & $228(62)$ & $109(59)$ & $26(56)$ & & & \\
\hline 2010-2012 & $166(28)$ & $90(25)$ & $60(33)$ & $16(35)$ & & & \\
\hline \multicolumn{8}{|l|}{ Initial setting of TN diagnosis } \\
\hline ER & $106(16)$ & $34(8)$ & $60(31)$ & $12(26)$ & $<0.001$ & $<0.001$ & 0.493 \\
\hline Internal medicine & $115(18)$ & $63(15)$ & $46(23)$ & $6(13)$ & 0.015 & 0.632 & 0.108 \\
\hline Neurology & $166(25)$ & $112(27)$ & $42(21)$ & $12(26)$ & 0.115 & 0.787 & 0.543 \\
\hline Neurosurgery & $54(8)$ & $38(9)$ & $10(5)$ & $6(13)$ & 0.074 & 0.444 & 0.057 \\
\hline Other HFMG & $20(3)$ & $13(3)$ & $7(4)$ & $0(0)$ & 0.80 & 0.215 & 0.188 \\
\hline Outside HFMG & $191(29)$ & $149(36)$ & $31(16)$ & $11(23)$ & $<0.001$ & 0.076 & 0.216 \\
\hline
\end{tabular}

* Data are number of patients (\%) unless otherwise indicated.

$\dagger$ Data were missing in 57 patients.

For patients with an initial diagnosis performed in our institution's ER, internal medicine, or other HFMG department (such as the pain clinic, ophthalmology, otolaryngology, and psychiatry), there were no differences among the races in the likelihood of going on to see an HFMG neurologist or neurosurgeon (Table 4). Similarly, among the patients with an initial diagnosis in our institution's neurology department (166 patients), the overall percentage of patients subsequently seen by neurosurgery was $30 \%$, with no significant differences found among the racial groups (white 29\%, black 38\%, and other 17\%, overall $p=0.296$ ). Taken together, these findings reveal a racial difference in the site of initial diagnosis but not in the likelihood of subsequently being seen in neurology or neurosurgery if one is first seen in other HFMG departments.

\section{Pharmacological Treatment of TN}

White patients were more likely to have used multiple medications for their TN as compared with black patients ( $29 \%$ vs $19 \%, \mathrm{p}=0.005)$. Fewer than $50 \%$ of patients diagnosed after the 2008 publication of the EFNS-AAN guidelines for medical therapy for TN, across all races, were on medications sanctioned by the guidelines (Table 5). There was a trend toward black patients having a higher rate of EFNS-AAN-sanctioned medications as compared with white patients; however, this difference did not reach statistical significance $(56 \%$ vs $44 \%, \mathrm{p}=0.060)$.

\section{Discussion}

The 2002 Institute of Medicine report "Unequal Treatment" summarized a large of body of published literature 
TABLE 2. Multivariate logistic regression results for the outcome of undergoing at least 1 procedure to treat $\mathrm{TN}^{*}$

\begin{tabular}{|c|c|c|c|c|}
\hline \multirow[b]{2}{*}{ Variable } & \multicolumn{2}{|c|}{ All TN Patients $(\mathrm{n}=652)$} & \multicolumn{2}{|c|}{$\begin{array}{l}\text { TN Patients Referred or Seen in } \\
\text { HFMG Neurosurgery }(n=266)\end{array}$} \\
\hline & OR $(95 \% \mathrm{Cl})$ & $p$ Value & OR $(95 \% \mathrm{Cl})$ & $\mathrm{p}$ Value \\
\hline \multicolumn{5}{|l|}{ Race } \\
\hline White vs black & $2.29(1.42-3.71)$ & $<0.001$ & $1.68(0.78-3.59)$ & 0.184 \\
\hline White vs other & $2.48(1.11-5.55)$ & 0.027 & $2.93(0.98-8.77)$ & 0.054 \\
\hline Black vs other & $1.08(0.46-2.54)$ & 0.862 & $1.75(0.52-5.84)$ & 0.364 \\
\hline Increase of $10 \mathrm{yrs}$ in age & $0.99(0.88-1.13)$ & 0.903 & $0.94(0.77-1.15)$ & 0.564 \\
\hline Increase of $\$ 10,000$ in median household income & $0.97(0.90-1.05)$ & 0.407 & $0.89(0.79-0.99)$ & 0.028 \\
\hline Type of insurance & & 0.472 & & 0.567 \\
\hline Private vs none & $0.80(0.46-1.39)$ & & $1.57(0.72-3.44)$ & \\
\hline Medicare vs none & $0.56(0.30-1.07)$ & & $0.95(0.39-2.31)$ & \\
\hline Medicaid vs none & $0.72(0.21-2.51)$ & & $2.31(0.23-22.6)$ & \\
\hline Other vs none & $0.73(0.21-2.58)$ & & $1.85(0.16-20.9)$ & \\
\hline
\end{tabular}

* Although whites were more likely to undergo a procedure in general, there was no statistically significant racial bias between blacks and whites among those seen by HFMG neurosurgery. Of those patients seen by HFMG neurosurgery, the wealthier patients were slightly less likely to undergo a procedure.

on racial/ethnic inequalities in the delivery and quality of health care. ${ }^{16}$ A large number of studies since then have continued to document disparities in various dimensions of medical care, including cancer care, myocardial infarction care, diabetes management, and asthma care. ${ }^{5,6,8,11}$ The studies by Kalkanis et al. and Wang et al. demonstrated a significant racial bias in the use of inpatient surgical procedures for TN in the US.12,18 Our findings on disparities in treatment among patients seen in a single organization are consistent with the results of those studies.

There is no evidence that different racial groups are more or less likely to suffer from TN, so a difference in the rates of disease incidence does not seem to be a likely explanation for observed differences in procedural treatment rates.

Our primary objective was to identify how race could influence the ways in which patients with TN were diagnosed, triaged to specialty clinics, and, ultimately, medically and surgically treated. While it is clear that white patients underwent procedures for $\mathrm{TN}$ more frequently than other races at our institution, these differences do not appear to stem from differences in referral patterns from

TABLE 3. Time between diagnosis and procedure for each race group among 160 patients who underwent at least 1 procedure*

\begin{tabular}{ccccc}
\hline Racial Group & No. of Patients & Median & Range & IQR \\
\hline White & 118 & 2 & $0-37$ & $0-5$ \\
\hline Black & 34 & 2 & $0-11$ & $0-4$ \\
\hline Other & 8 & 1.5 & $0-22$ & $0.5-6$ \\
\hline
\end{tabular}

* Thirty patients ( 23 white and 7 black) of the 190 who had undergone at least 1 procedure had a missing year of diagnosis or of first procedure and thus were excluded from analysis. Median, range, and interquartile range expressed in years. Medians and ranges are provided because the extreme outliers influenced the means and standard deviations. None of the differences between the race groups were significant (white vs black $p=0.733$, white vs other $p=0.874$, and black vs other $p=0.821$ ). within our institution. Blacks and whites were equally likely to undergo surgery once they were seen by an HFMG neurosurgeon. Neither was there a difference in the type of procedure that blacks and whites were likely to undergo among MVD, PCTR, and SRS. Blacks and whites were equally likely to be seen by a neurosurgeon after being seen by an HFMG ER physician, internal medicine practitioner, or neurologist. However, the majority of patients who received outside referrals to HFMG neurologists and neurosurgeons were white. This finding may be attributable to racial disparities outside HFMG or differences in patterns of referral by outside clinicians to HFMG versus other neurosurgeons in the region who treat $\mathrm{TN}$.

A possible explanation for the racial disparity in the referral pattern may stem from cultural beliefs and perceptions about surgical and nonsurgical treatments. Goldstein et al. found that inner-city African Americans were more likely to express interest in complementary and alternative medicine? Such opinions expressed to a patient's primary care physician or outside referring physician may account for a decrease in neurosurgical referrals. In addition, culture-specific values influence patient roles and expectations, how much information about illness and treatment is desired, sex and family roles, and processes of decision making. In the African American culture, illness is sometimes seen as a natural event, occurring according to "God's plan." Furthermore, huge emphasis is placed on the importance of family and church. In addition, if surgery is decided on, the logistics of the peri- and postoperative period can pose a huge strain on a family.

Chan et al. found that similar racial disparities regarding surgical treatment exist within the neurosurgical realm. ${ }^{3}$ African Americans were less likely to undergo electrode placement for deep brain stimulation for Parkinson's disease despite the fact that they, compared with other races, are more often discharged from larger urban teaching hospitals with both deep brain stimulation capabilities and well-trained neurologists and neurosurgeons 
TABLE 4. Referral rates to neurology or neurosurgery from other HFMG clinical settings as stratified by race*

\begin{tabular}{|c|c|c|c|c|c|c|c|c|c|c|c|}
\hline \multirow[b]{2}{*}{$\begin{array}{l}\text { Initial Setting of } \\
\text { Diagnosis }\end{array}$} & \multicolumn{2}{|c|}{ All $(n=241)$} & \multicolumn{2}{|c|}{ White $(n=110)$} & \multicolumn{2}{|c|}{ Black $(n=113)$} & \multicolumn{2}{|c|}{ Other $(n=18)$} & \multicolumn{3}{|c|}{$p$ Value } \\
\hline & No. & $\begin{array}{l}\text { No. w/ } \\
\text { Ref (\%) }\end{array}$ & No. & $\begin{array}{l}\text { No. w/ } \\
\text { Ref (\%) }\end{array}$ & No. & $\begin{array}{l}\text { No. w/ } \\
\text { Ref (\%) }\end{array}$ & No. & $\begin{array}{l}\text { No. w/ } \\
\text { Ref (\%) }\end{array}$ & $\begin{array}{c}\text { White vs } \\
\text { Black }\end{array}$ & $\begin{array}{c}\text { White vs } \\
\text { Other }\end{array}$ & $\begin{array}{c}\text { Black vs } \\
\text { Other }\end{array}$ \\
\hline ER & 106 & $41(39)$ & 34 & $13(38)$ & 60 & $22(37)$ & 12 & $6(50)$ & 0.879 & 0.476 & 0.387 \\
\hline Internal medicine & 115 & $55(48)$ & 63 & $30(48)$ & 46 & $23(50)$ & 6 & $3(50)$ & 0.806 & 0.502 & 0.442 \\
\hline Other HFMG location & 20 & $10(50)$ & 13 & $6(46)$ & 7 & $4(57)$ & 0 & 0 & 0.639 & NA & NA \\
\hline
\end{tabular}

$\mathrm{NA}=$ not applicable; Ref $=$ referral.

* There were no statistically different rates of referral to neurology or neurosurgery based on race within the different clinical settings. There were significant differences in referral rates to neurology or neurosurgery based on the initial setting of diagnosis, and this difference was consistent across racial groups.

to perform such procedures. This finding suggests that members of different races may hold differing views and levels of comfort with surgical procedures.

Our study showed that a large percentage of patients were not treated with appropriate medications after the dissemination of the EFNS-AAN guidelines. Although not statistically significant, there was a trend for poorer adherence to the guidelines in white patients. This may reflect the fact that the majority of white patients were referred from outside of HFMG. Our study also demonstrated that only a minority of patients seen by ER, internal medicine, and other practitioners at the HFMG subsequently go on to see a neurologist or neurosurgeon. It is unclear if this is attributable to spontaneous or pharmacological improvement in patient pain or whether the patients chose to see neurologists and neurosurgeons outside of HFMG.

Other minor determinants include health literacy, support structure, psychosocial factors, and social values. ${ }^{1}$ It is widely known that different cultures have different views on what causes illness, how it should be addressed, and who should be involved in the process. Cultural differences affect patient attitudes about medical care and their ability to understand, manage, and cope with the course of an illness, the meaning of a diagnosis, and the consequences of medical treatment. Additionally, The Commonwealth Fund reports that blacks commonly experience disrespect in the health care setting. Assumptions based on negative societal images of blacks contribute to the negative experiences many encounter when they present for health care, thus creating a lack of trust among black patients when the treating physician is a different race. With all these factors in play, primary care physicians outside the HFMG who encounter black patients with TN may decide against neurological referrals in response to the patients' wishes.

This retrospective institutional study suffers from a number of limitations. Because we could not control outcome assessment and we had to rely on the accurate record keeping of other individuals, our study may suffer from sampling or information bias. We attempted to minimize this bias by individually reviewing each patient's medical records from the time of his or her first encounter at our institution and by excluding patients who were subsequently diagnosed as having facial pain that was not consistent with TN. By doing this, we were able to eliminate patients whose description of their facial pain characteristics did not fit the recorded diagnostic code. Data regarding the reported severity of symptoms or visual analog scale scores are not available in our database. While this information may be available in patient records, it is not routinely documented in every facial pain encounter; therefore, we were unable to ascertain whether the severity of a patient's symptoms had an impact on their choice of treatment. We were unable to determine patient preferences regarding treatment options for TN. Established differences in pain thresholds and response to painful stimuli across ethnic backgrounds reported in the literature ${ }^{5}$ and cultural views toward surgery may have influenced our patients' decisions regarding specific treatment options. Future studies will address patient preferences and satisfaction with their care. Given the aforementioned limitations, it may be difficult to generalize our findings to other health care systems or to the general populace. However, our investigation is unique in that we are the first to examine disparities in the medical and surgical management of TN.

\section{Conclusions}

Racial inequalities in the diagnosis and management of chronic pain disorders are well reported in the literature. Our analysis revealed that race, rather than median household income or insurance coverage, was associated with the likelihood of undergoing a procedure for TN. However, once a patient was evaluated by an ER, internal medicine, neurology, or neurosurgery practitioner within the HFMG, both white and black patients underwent similar rates of procedures. There were no racial differences in the preferences for particular procedures, be it MVD,

TABLE 5. Use of AAN-EFNS-sanctioned medications in patients diagnosed after 2008

\begin{tabular}{lcccccccc}
\hline & & & & & \multicolumn{3}{c}{$p$ Value } \\
\cline { 7 - 9 } Variable & All Patients & White & Black & Other & White vs Black & White vs Other & Black vs Other \\
\hline Total no. of patients & 268 & 150 & 94 & 24 & & & \\
\hline Guideline medication (no. [\%]) & $130(49)$ & $66(44)$ & $53(56)$ & $11(46)$ & 0.059 & 0.866 & 0.354 \\
\hline
\end{tabular}


PCTR, or SRS. Therefore, addressing referral or treatment decision processes within the HFMG will not decrease racial disparities. Future efforts will be needed to examine regional or national databases that contain outpatient information and potentially target practitioners outside the HFMG. Adherence to EFNS-AAN guidelines for the pharmacological management of $\mathrm{TN}$ was equally poor for both whites and blacks.

\section{References}

1. Allendorfer JB, Szaflarski JP: Contributions of fMRI towards our understanding of the response to psychosocial stress in epilepsy and psychogenic nonepileptic seizures. Epilepsy Behav 35:19-25, 2014

2. Attal N, Cruccu G, Baron R, Haanpää M, Hansson P, Jensen TS, et al: EFNS guidelines on the pharmacological treatment of neuropathic pain: 2010 revision. Eur J Neurol 17:11131123, e67-e88, 2010

3. Chan AK, McGovern RA, Brown LT, Sheehy JP, Zacharia BE, Mikell CB, et al: Disparities in access to deep brain stimulation surgery for Parkinson disease: interaction between African American race and Medicaid use. JAMA Neurol 71:291-299, 2014

4. Cruccu G, Gronseth G, Alksne J, Argoff C, Brainin M, Burchiel K, et al: AAN-EFNS guidelines on trigeminal neuralgia management. Eur J Neurol 15:1013-1028, 2008

5. Drake BF, Keane TE, Mosley CM, Adams SA, Elder KT, Modayil MV, et al: Prostate cancer disparities in South Carolina: early detection, special programs, and descriptive epidemiology. J S C Med Assoc 102:241-249, 2006

6. Gaskin DJ, Thorpe RJ Jr, McGinty EE, Bower K, Rohde C, Young JH, et al: Disparities in diabetes: the nexus of race, poverty, and place. Am J Public Health 104:2147-2155, 2014

7. Goldstein JN, Ibrahim SA, Frankel ES, Mao JJ: Race, pain, and beliefs associated with interest in complementary and alternative medicine among inner city veterans. Pain Med 16:1467-1474, 2015

8. Green CR, Hart-Johnson T: The impact of chronic pain on the health of black and white men. J Natl Med Assoc 102:321-331, 2010

9. Guardiani E, Sadoughi B, Blitzer A, Sirois D: A new treatment paradigm for trigeminal neuralgia using Botulinum toxin type A. Laryngoscope 124:413-417, 2014

10. Hupp WS, Firriolo FJ: Cranial neuralgias. Dent Clin North Am 57:481-495, 2013

11. Jean-Pierre P, Fiscella K, Griggs J, Joseph JV, Morrow G,
Carroll J, et al: Race/ethnicity-based concerns over understanding cancer diagnosis and treatment plan. J Natl Med Assoc 102:184-189, 2010

12. Kalkanis SN, Eskandar EN, Carter BS, Barker FG II: Microvascular decompression surgery in the United States, 1996 to 2000: mortality rates, morbidity rates, and the effects of hospital and surgeon volumes. Neurosurgery 52:1251-1262, 2003

13. Katusic S, Beard CM, Bergstralh E, Kurland LT: Incidence and clinical features of trigeminal neuralgia, Rochester, Minnesota, 1945-1984. Ann Neurol 27:89-95, 1990

14. Katusic S, Williams DB, Beard CM, Bergstralh EJ, Kurland LT: Epidemiology and clinical features of idiopathic trigeminal neuralgia and glossopharyngeal neuralgia: similarities and differences, Rochester, Minnesota, 1945-1984. Neuroepidemiology 10:276-281, 1991

15. Siqueira SR, Teixeira MJ, Siqueira JT: Clinical characteristics of patients with trigeminal neuralgia referred to neurosurgery. Eur J Dent 3:207-212, 2009

16. Smedley BD, Stith AY, Nelson AR (eds): Unequal Treatment: Confronting Racial and Ethnic Disparities in Health Care. Washington, DC: Institute of Medicine, 2003

17. van Hecke O, Austin SK, Khan RA, Smith BH, Torrance N: Neuropathic pain in the general population: a systematic review of epidemiological studies. Pain 155:654-662, 2014

18. Wang DD, Ouyang D, Englot DJ, Rolston JD, Molinaro AM, Ward M, et al: Trends in surgical treatment for trigeminal neuralgia in the United States of America from 1988 to 2008. J Clin Neurosci 20:1538-1545, 2013

\section{Disclosures}

The authors report no conflict of interest concerning the materials or methods used in this study or the findings specified in this paper.

\section{Author Contributions}

Conception and design: Reinard, Schwalb. Acquisition of data: Reinard, Jelsema. Analysis and interpretation of data: Reinard, Schultz, Schwalb. Drafting the article: Reinard, Nerenz, Schwalb. Critically revising the article: Reinard, Nerenz, Basheer, Tahir, Schultz, Malik, Air, Schwalb. Reviewed submitted version of manuscript: Reinard.

\section{Correspondence}

Kevin Reinard, Department of Neurosurgery, K-11, Henry Ford Health System, 2799 W. Grand Blvd., Detroit, MI 48202. email: kevinreinard@gmail.com. 